\section{Ingestion of unusual items by wetland birds in urban landscapes}

\author{
Abey Francis ${ }^{1}$, B. Anjan Kumar Prusty ${ }^{2, *}$ and \\ P. A. Azeez ${ }^{3}$ \\ ${ }^{1}$ School of Life Sciences, Devi Ahilya Vishwavidyalaya, \\ Indore 452 001, India \\ ${ }^{2}$ Department of Natural Resources Management and Geoinformatics, \\ Khallikote University, G-Max Building on NH-16, Konisi, \\ Berhampur 761 008, India \\ ${ }^{3}$ Sálim Ali Centre for Ornithology and Natural History, Anaikatti, \\ Coimbatore 641 108, India
}

In view of the variety of waste items casually disposed off by humans, a survey was conducted in two cities, Indore and Coimbatore, in roosting sites of colonial birds looking for unusual items in their food. Of the 891 regurgitated pellets of birds examined, about $53 \%$ in Coimbatore and $14 \%$ in Indore contained rubber bands, rubber balloons and small plastic debris. Rubber bands $(95.3 \%)$, balloon $(2.35 \%)$, plastic bits (1.41\%) and plastic cap $(0.94 \%)$ were found in the pellets. Among the rubber bands, red was the predominant colour $(73.1 \%)$ followed by green $(25 \%)$ and yellow (1.9\%). These findings show that the birds misjudge an artefact as natural prey. The highly corroded rubber bands indicate the leaching of chemicals (like plasticizers and bisphenols), many of which are potential endocrine disruptors. The potential hazard from such leachable contaminants needs to be further studied. The present study also highlights the need for managing such deceptive wastes cautiously to safeguard wildlife.

Keywords: Pellets, prey mimicry, regurgitation, rubber band, solid waste management, wetland birds.

POLLUTION of the environment with non-edible artefacts that looks like natural food items pose threats to invertebrates, fishes, reptiles, birds and mammals. There are cases of platypus deep wounded when a plastic bag got wrapped around its body ${ }^{1}$, sea turtles mistaking plastic bags for jellyfish ${ }^{2}$, plastic straw and forks stuck in the nostrils of Olive Ridley Turtles ${ }^{3}$, and livestock and wild animals, including elephants, dying after ingesting plastic food packages ${ }^{4,5}$. Thus, careless solid waste disposal is a major threat to animals and birds, especially in India because dumping of industrial and municipal waste in nearby lakes, wetlands and rivers is a practice ${ }^{6}$.

Health of wildlife can be affected by ingestion of nonedible, anthropogenic debris that resembles natural prey. There have been fatal instances of rubber bands stuck in the intestines blocking the passage of food in pet birds ${ }^{7}$. The first evidence of massive ingestion of rubber bands was from an earthworm consumer, the White Stork

\footnotetext{
*For correspondence. (e-mail: bakprusty@khallikoteuniversity.ac.in)
}

(Ciconia ciconia), in France ${ }^{8}$ where $26 \%$ of dead storks had rubber bands in digestive tracts. Henry et al. ${ }^{8}$ reported the birds often snapping at the stretchy strips, mistaking them for worms, at times leading to deadly consequences. Dozens of ducks had to be rescued in West Sussex after they mistook red rubber bands for worms and devoured them ${ }^{9}$. The problem arose because the bands, used for bundling mails discarded on the ground were washed down during rains, depositing them in the littoral zone of the lake. More than adults, immature birds were victims of such behaviours because of inability in discerning and regurgitating non-edible items, as well as higher frequency of such items in the rubbish ${ }^{10}$.

In India, the Wetlands (Conservation and Management) Rules, 2017 bar dumping solid waste in wetlands or along its banks. However, as enforcement of the same remains a challenge, numerous wetlands are still subject to waste dumping. Although many wetlands (bird habitats) are said to be clean ${ }^{11}$, waste items particularly the smaller ones like rubber bands, bottle caps, polystyrene balls and straws are ignored. They find their way to the water bodies and largely settle in shallow waters. Of such wastes, small products such as rubber bands usually reach quasi-wild places, lakes or wetlands, with visitors (tourists) bringing food for own use or to feed birds, fishes or others there as ritual or recreation. Hence, this study was undertaken to examine these artefacts, primarily rubber bands, at times looking like live worms in water, being eaten by wild birds. This was done by examining regurgitates of colonial roosting birds in two cities in India, Coimbatore in the south and Indore in central India.

The survey was conducted from February through May 2014 in Indore and Coimbatore, having several wetlands within their urban limits. Indore is considered the most populous (1.96 million as per Census of India-2011) city in central India and the commercial capital of Madhya Pradesh. Of the 15 wetlands in and around the city (Figure 1), Sirpur Lake, spread over 600 acres, is a rain-fed lake built almost a century ago by the erstwhile rulers of the state, the Holkars, as source of water for the city. A popular tourist spot, the lake is situated in the outskirts of the city, providing much-required open space for the people and habitats for several birds ${ }^{12}$. It is a wetland of national importance under the National Wetland Conservation Programme (NWCP) of Government of India ${ }^{13}$. The lake offers an idyllic environment for birds, both resident and migratory. Nonetheless, there have been grave pressures on this lake. Part of its terrestrial area is occupied by squatter settlements. It receives municipal sewage round the year and open defecation is another issue ${ }^{14}$. Ecologically, the proximity of the lake to the city seems to be intimidating to wild birds. Yet, the lake, as of now, serves the city by storing rainwater and providing recreational space for people.

Coimbatore is the second largest city (population 3.473 million as per Census of India-2011) in Tamil Nadu and 


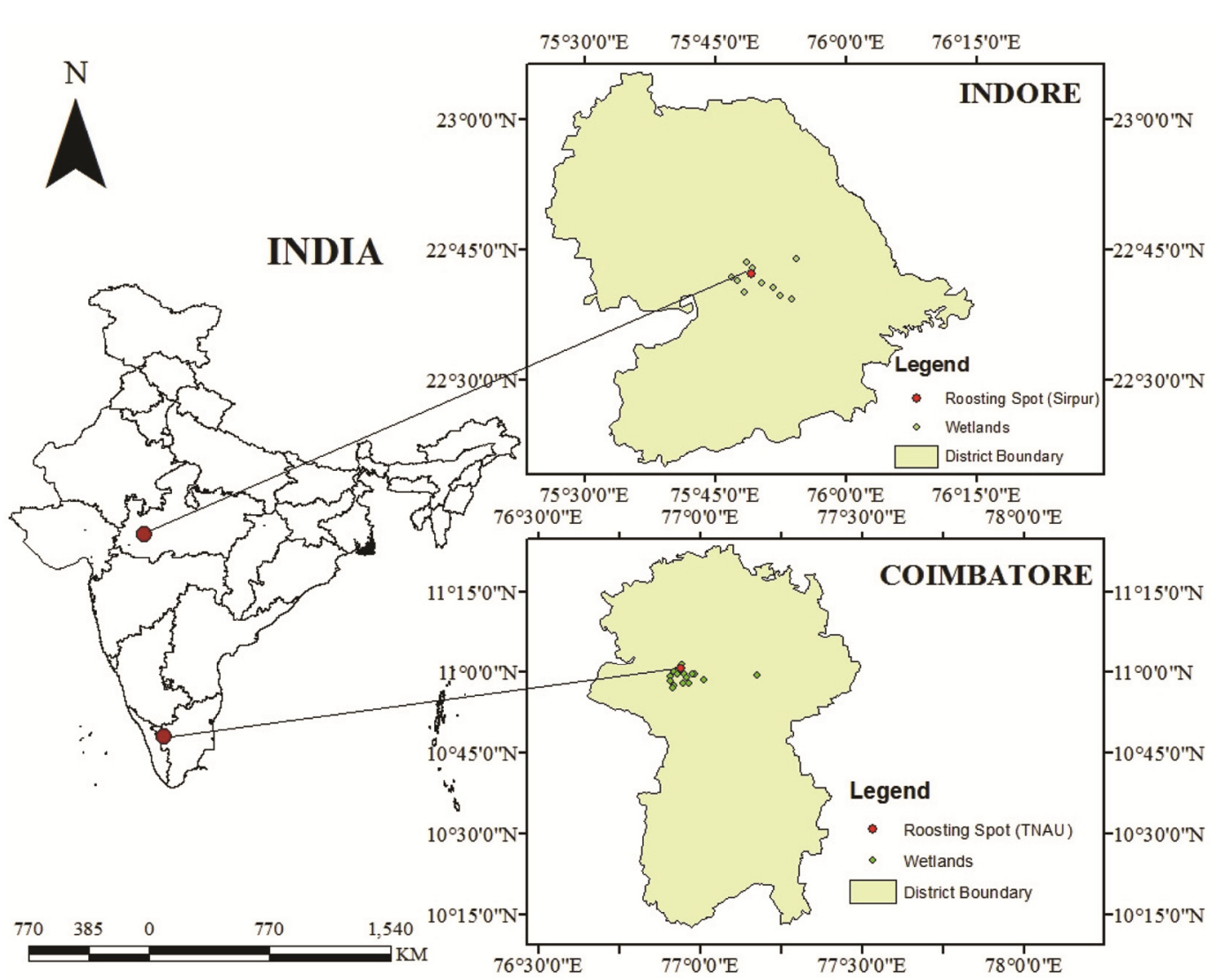

Figure 1. Study area map with sampling locations.

one of the fast-growing cities in South India. It has currently 24 wetlands within city limits and its periphery ${ }^{15}$. Most of these wetlands are fed by the River Noyyal, originating in the foothills of Western Ghats. More than 135 species of resident and migratory birds have been reported from the Coimbatore city ${ }^{16}$. Within the city limits, large number of birds congregate in a patch of woods (mainly banyan), a roosting site for decades, in the Tamil Nadu Agriculture University (TNAU) campus.

At Indore, two roosting sites near Sirpur Lake (Figure 1) were selected for this study. The first site (S-1, $22^{\circ} 42^{\prime} 14^{\prime \prime} \mathrm{N}, 75^{\circ} 49^{\prime} 5^{\prime \prime} \mathrm{E}$ ) is a grove with banyan (Ficus benghalensis) and peepal (Ficus religiosa) trees where a flock of Little Cormorant (Microcarbo niger), Cattle Egret (Bubulcus ibis) and Common Myna (Acridotheres tristis) roost. The second site (S-2, $22^{\circ} 42^{\prime} 16^{\prime \prime} \mathrm{N}$, $75^{\circ} 49^{\prime} 7^{\prime \prime} \mathrm{E}$ ), 75-80 $\mathrm{m}$ away from $\mathrm{S}-1$, is a grove of honey locust trees (Gleditsia triacanthos) where largely Indian Pond Heron (Ardeola grayii) were roosting. In Coimbatore, the study site was a thick grove $\left(11^{\circ} 0^{\prime} 38^{\prime \prime} \mathrm{N}\right.$, $76^{\circ} 56^{\prime} 14^{\prime \prime} \mathrm{E}$ ) (Figure 1) of banyan in the TNAU campus. Cattle Egret, Black-headed or Oriental White Ibis (Threskiornis melanocephalus), Intermediate or Median Egret (Mesophoyx intermedia), Red-naped or Black Ibis (Pseudibis papillosa), Little Cormorant (Phalacrocorax niger) and House Crow (Corvus splendens) were roosting here. This study site, less than a kilometre of radial dis- tance from the nearest Selvampathy Lake is a lesser disturbed roosting site in the city. The birds often arrive there for roosting early in the evening until sunset. The birds roosting at each site were counted daily in the morning $(0700$ to $0900 \mathrm{~h})$ and evening (1730 to $2000 \mathrm{~h}$ ) for 52 days from February to May 2014 following Bibby et $a l .{ }^{17}$. The birds were identified using methods followed by Ali and Ripley ${ }^{18}$ and Grimmett et al. ${ }^{19}$ and the nomenclature followed was from Manakadan and Pittie ${ }^{20}$.

To identify the unusual items ingested by the birds, regurgitated pellets were collected daily from both the sites in the morning after the birds left for foraging. Quadrates were laid to collect the regurgitated pellets. Under the canopy of each roost tree, transparent polythene sheets $\left(1 \times 1 \mathrm{~m}^{2}\right)$ were spread out randomly. The size of the sheet was decided based on prior repeated observations to reduce disturbance due to wind and animal movements which larger sheets are more prone. At Sirpur site, eight quadrates (four each at S-1 and S-2) were laid during February-March 2014. In the TNAU campus, 10 quadrates were laid during March-May 2014. From each quadrate, where the species roosting above was recorded, regurgitates were collected, numbered and stored in preacid treated plastic containers at $4^{\circ} \mathrm{C}$ till further processing. Care was taken to ensure that the shape and size of regurgitates remained intact until further dismemberment and processing to identify the contents. Apart 


\section{RESEARCH COMMUNICATIONS}

Table 1. Roosting birds in each of the study sites and pellets with entangled rubber bands

\begin{tabular}{|c|c|c|c|c|}
\hline \multirow[b]{2}{*}{ Site no. } & \multicolumn{2}{|r|}{ Roosting birds } & \multicolumn{2}{|c|}{ Regurgitated pellets } \\
\hline & Species & Major food items & Total number & With rubber bands \\
\hline \multirow[t]{2}{*}{1} & Cattle Egret & $\begin{array}{l}\text { Worms, lies, crickets, grasshoppers, cicadas, maggots, amphibians, } \\
\text { reptiles, spiders, crayfish, millipedes, centipedes and fish }{ }^{46}\end{array}$ & & \\
\hline & Little Cormorant & Fishes, amphibians and crustaceans & 250 & 36 \\
\hline 2 & Indian Pond Heron & Crustaceans, worms, leeches, insects, fishes and tadpoles ${ }^{47}$ & 34 & 2 \\
\hline $\mathrm{B}$ & TNAU Campus, Coimbatore & & & \\
\hline \multirow[t]{5}{*}{1} & Cattle Egret & $\begin{array}{l}\text { Worms, flies, crickets, grasshoppers, cicadas, maggots, amphibians, } \\
\text { reptiles, spiders, crayfish, millipedes, centipedes and fish }\end{array}$ & & \\
\hline & Black-headed Ibis & Fish & 607 & 320 \\
\hline & Intermediate Egret & Fish & & \\
\hline & Little Cormorant & Fish & & \\
\hline & House Crow & Omnivore - opportunistic feeder & & \\
\hline
\end{tabular}

from the pellets obtained in quadrats, fresh, wet and clean pellets those found on the ground nearby were collected for examination. To confirm the species that had evicted each pellet, the location of the pellet under the tree, the bird species sitting/roosting just above it, shape and size of regurgitates and known composition of the bird's diet was used. The sampling and counting of unusual items entangled in the pellets were only considered.

In Sirpur Lake, more than 1000 birds roosted whereas 2300 birds were roosted in TNAU campus. The average number of individuals of each species based on the daily counts of birds roosting at each site and the number of regurgitates is given in Table 1 .

The striking observation of the present study was the frequency of coloured rubber bands entangled in regurgitated pellets collected at both Indore and Coimbatore. The percent of occurrence (number of pellets with rubber bands $\times 100 /$ total number of pellets) of rubber bands in the pellets (in parenthesis) at the study sites were 320 (52.72\% - TNAU), 36 (14.4\% - Site-1, Indore) and 02 (5.88\% - Site-2, Indore) (Table 1 and Figure 2). Of the 250 regurgitated pellets from S-1, 36 contained rubber bands in it (Figure 3), whereas of the 34 pellets from S-2, where 18 Indian Pond herons roosted, only 2 contained rubber bands; in total 38 pellets with rubber bands from both sites at Indore. Of 607 regurgitated pellets collected from TNAU campus, 320 contained rubber bands (Figure 2). Numerous discoloured rubber bands with worn pellets, disgorged days before our sampling, lying underneath the tree, indicate the severity of the ingestion of these extraneous items (Figure 4). Careful observation of the regurgitations from Indore and Coimbatore reveals that a major chunk of the rubber bands are red (with a few yellow and green ones) (Figures 3 and 4) and the colour wise composition was red $(73.1 \%)>$ green $(25 \%)>$ yellow $(1.9 \%)$. Moreover, some of the pellets also had balloons and plastic bits (Figure 5). The percentage composition of different artefacts found in the pellets was rubber band $(95.3)>$ balloon $(2.35)>$ plastic bits $(1.41)>$ plastic cap (0.94).

The present study finds a notable number of rubber bands in the regurgitated pellets of colonial roosting birds in both Indore and Coimbatore. The presence of such items in the pellets is possibly more because of ingestion by misidentification as prey items and would be of dangerous consequence for the species. Rubber bands were found more in pellets from species such as Cattle Egret that feed on a variety of organisms than species more specific to fishes (such as Little Cormorant). The pellets with rubber bands were seen more at specific spots in some quadrates, suggesting certain individuals (each bird is said to prefer roosting on specific spots on their usual trees ${ }^{21,22}$ ) to be more prone to ingest such artefacts. That would possibly be because of their preferred feeding location, habits or persistent individual-specific misidentification.

Foraging microhabitats also seem to determine the frequency of rubber bands in the pellets. In systems like wetlands, those species feeding in shallow areas are likely to be deceived by rubber bands looking like edible worms, as evident from Little cormorants, foraging in deeper water, having lesser frequency of bands in pellets than Cattle egrets. Studies have also found species feeding primarily by diving and pirating ingesting less plastic items ${ }^{23}$. Birds feeding on squids and crustaceans showed far higher frequency of ingesting plastics than purely fish-eating birds ${ }^{24}$, possibly for the supple plastic items appearing like translucent prey in water. It has been recently reported that apart from relatively visible items such as rubber bands, smaller plastic items are also consumed by a large number of birds and other organisms throughout the world ${ }^{25}$. Thus, ingestion of artificial 


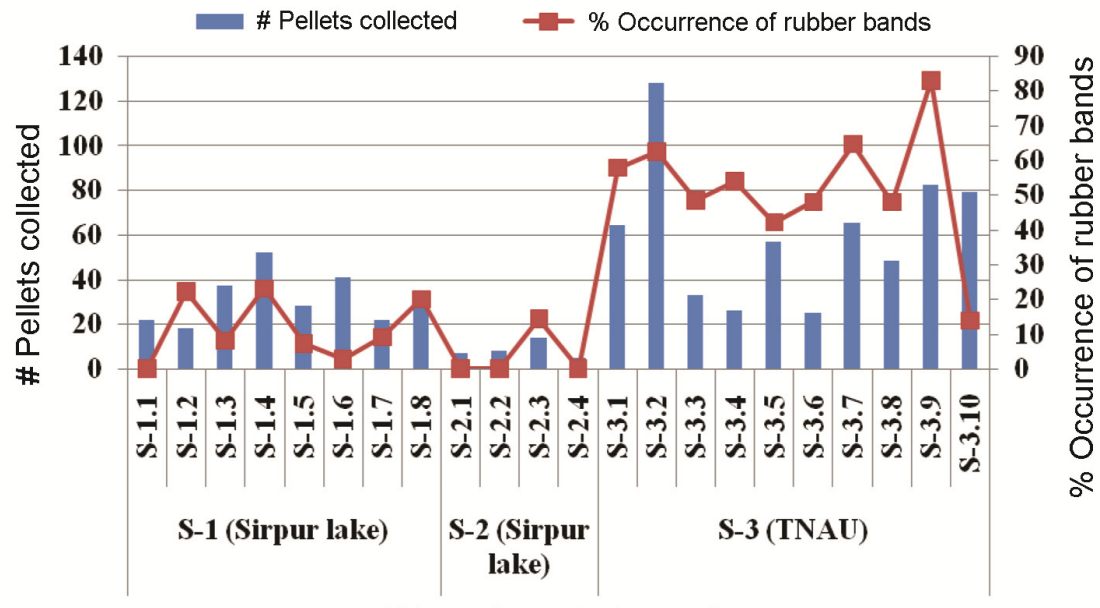

Site and quadrate number

Figure 2. Quadrate $\left(1 \times 1 \mathrm{~m}^{2}\right)$ wise distribution of pellets.
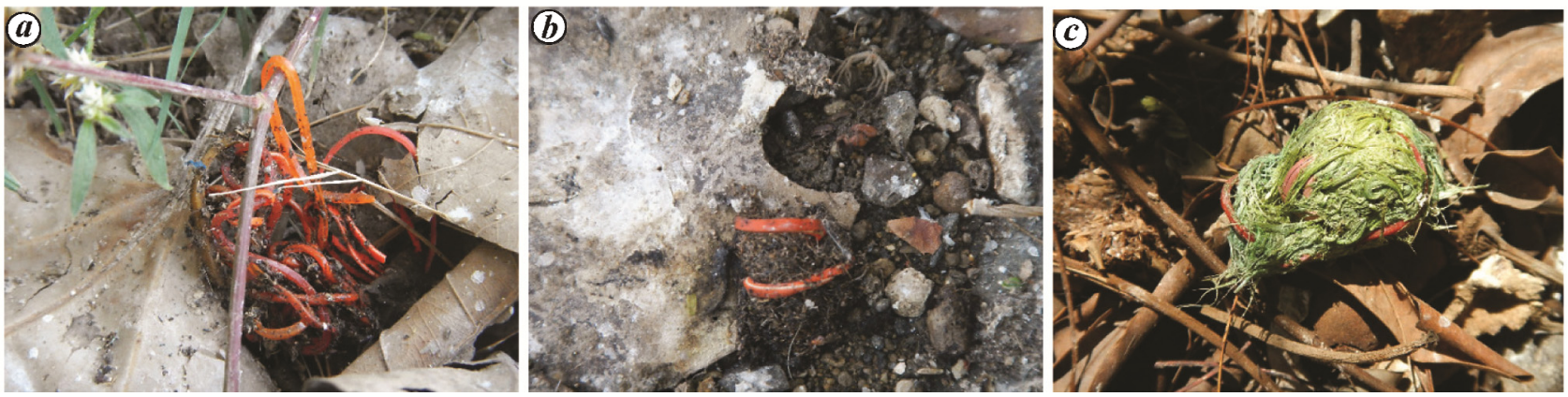

Figure 3. Rubber bands in regurgitated pellets of (a) Cattle Egret, (b) Little Cormorant and (c) Indian Pond Heron at Sirpur Lake.

polymer products (pulverized, micro and nano plastics) has become a serious threat ${ }^{26}$.

Reportedly nearly one-third of the fish in the Atlantic Ocean have plastic debris in stomachs. Broken-offs from synthetic monofilament fishing net, called 'ghost nets', are difficult for marine creatures and birds to detect, occasionally mistaking them for prey ${ }^{27,28}$. Globally marine human-made debris has affected 267 species; $86 \%$ of sea turtles, $44 \%$ of seabirds and $43 \%$ of marine mammals ${ }^{29}$. According to a study in USA, of 1033 birds collected off the coast, $55 \%$ had plastic in their gut, due to their habit of selecting prey based on colour and hence mistaking coloured polymers for prey items ${ }^{29,30}$. Such ingested items obstruct gastric enzyme release and lessen feeding stimulus causing low food uptake, internal organ injuries $^{31}$ and reproductive failure ${ }^{32}$.

Red was the preferred colour in the rubber bands found in regurgitated pellets, thus giving an impression that the birds might be confusing these items as a worm or the common red-worms seen in water. The rubber balloons and other such plastic items, in the regurgitations from TNAU, were coloured, indicating the birds' tendency to get attracted to bright and flaccid objects ${ }^{33}$. The surpris- ing misjudgement by the birds warns about the unforeseen ways in which solid wastes disposal affect organisms. Solid-waste close to water bodies, foraging grounds for several species, has insidious repercussions. Guptha et $a l .{ }^{34}$ present a typical scenario of one of the urban wetlands in Coimbatore where several species of birds forage and open dumping of municipal solid waste is seen. With a large quantity of solid waste (daily collection of 815 TPD as per $\mathrm{MUD}^{35}$ ), a notable portion of which is not covered by organized collection schemes, are disposed indiscreetly posing risk to birds. Similarly, Indore generates 685 TPD municipal solid wastes ${ }^{14}$. With such huge waste generation, the peri-urban wetlands or wilder areas in cities are victims, as municipal corporations generally locate waste dumpsites nearby such locations.

In the case of items such as rubber bands underwater, especially if the water is a bit murky, the birds might see such brightly coloured and wavering things as live natural preys. Obviously while competing for food, the temptation is to grab them. Mostly, such items when ingested are regurgitated. Birds regurgitate around 6-8 times in a day, but the frequency depends upon the food items. In the present study, most of our samples were collected during 

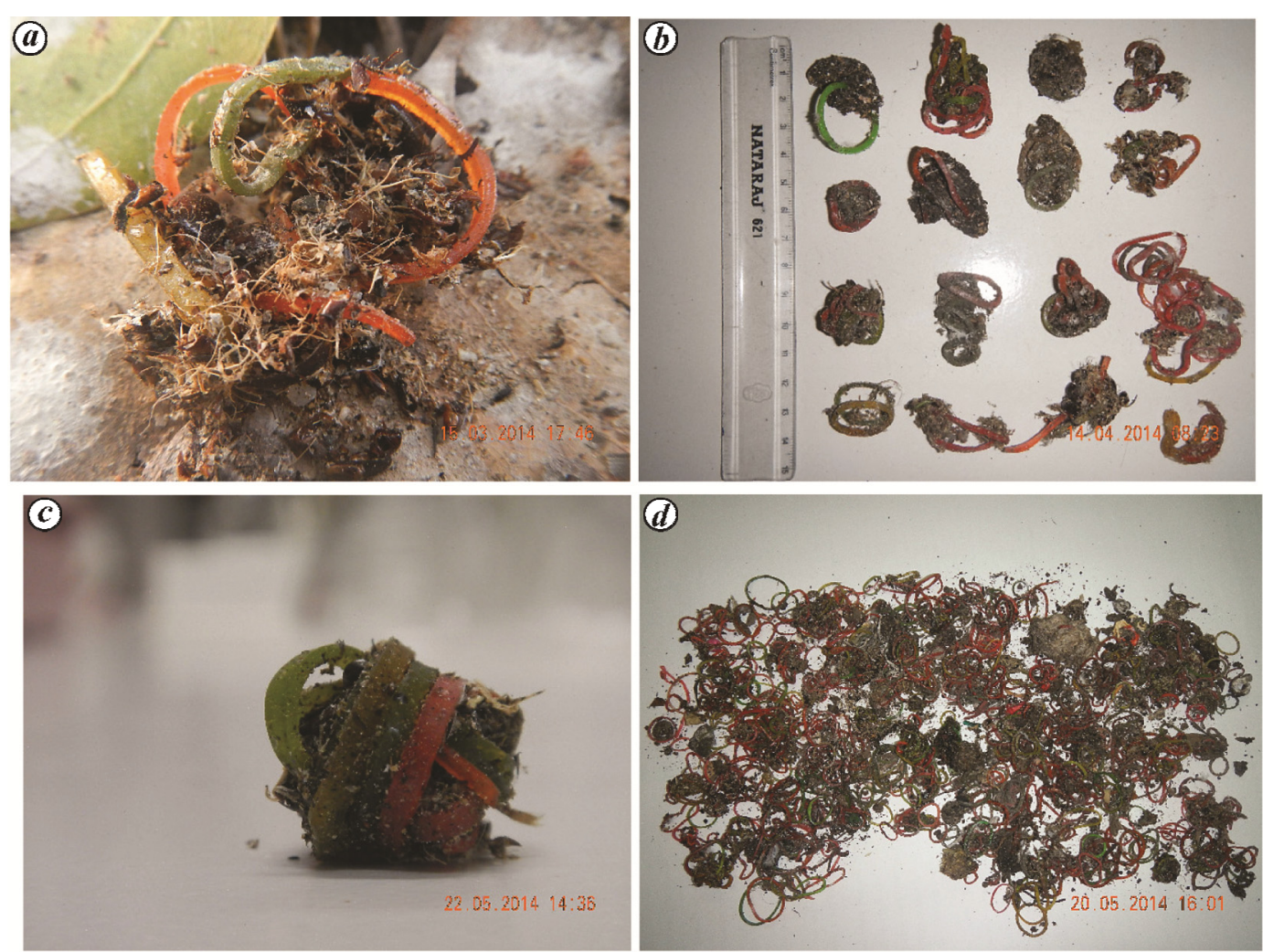

Figure 4. $\boldsymbol{a}$, Regurgitated pellet with coloured rubber bands at the TNAU site; $\boldsymbol{b}$, Overview of size of some selected pellets; $\boldsymbol{c}$, Rubber band, highly coiled, in a pellet; $\boldsymbol{d}$, Numerous coiled rubber bands in regurgitated pellets.
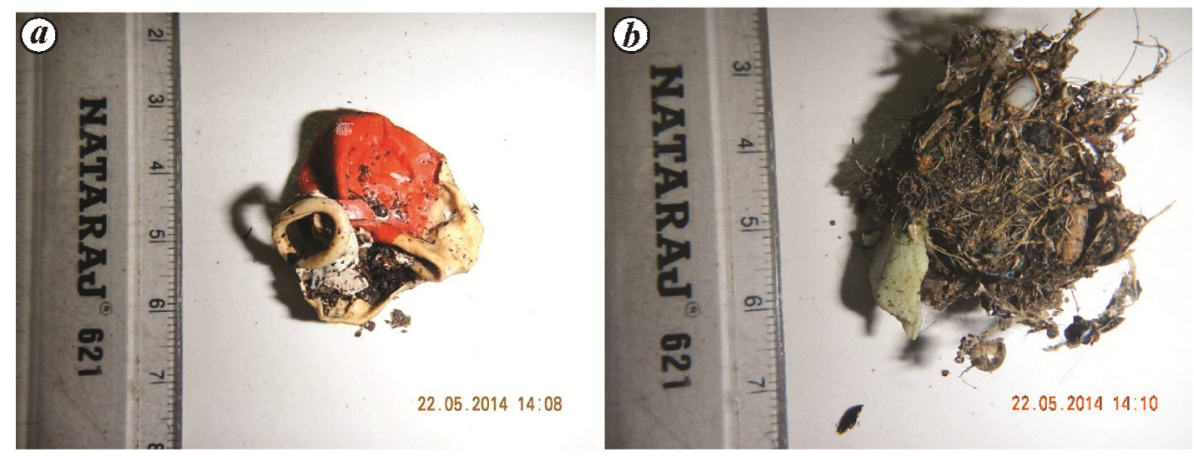

Figure 5. Rubber balloon $(\boldsymbol{a})$ and plastic bits $(\boldsymbol{b})$ in regurgitated pellets in TNAU campus.

early in the morning. Thus, the regurgitated pellets collected during the study would be from their last feeding bout. This also means that their last foraging grounds could be nearest to the roosting site, holding well in both the cases. However, after ingestion these items remain in their stomach for some time, causing a feeling of fullness, starvation and possibly death. Such incidences were reported from Midway Atoll ${ }^{36}$, parts of the Pacific ${ }^{37}$ and Atlantic ${ }^{38}$ Oceans. The artefacts in the guts are subject to digestive processes, and diverse chemicals such as plasticizers (phthalates), polyaromatic hydrocarbons, metals and others used in manufacture enter the birds' body ${ }^{31,32}$.
Ryan and Jackson ${ }^{39}$ discussed the harm from ingested plastic particles in the digestive system of seabirds. Xu et $a l .^{40}$ reported the toxicological implications of leachables from such artefacts. Chemicals such as plasticizers, known endocrine-disrupting chemicals, could disrupt normal hormonal functioning in birds ${ }^{31,32}$. Threads and fibres may obstruct the alimentary canal because they form dense, intertwined balls in gizzards, blocking the flow $^{41}$. Such intertwined balls observed in the present study can be fatal. Furthermore, there is the possibility of birds foraging on regurgitated pellets containing rubber bands under their roosting spots, if their foraging grounds 
are the same as their roosting spots, as is in the case of Sirpur Lake, leading to repeated ingestion and exposure of the items to the digestive processes. Apart from the visible plastic and rubber artefacts, a huge quantity of indiscernible microplastics and polymers enters the environment ${ }^{42,43}$. Given that, these artefacts are ingested by a diverse species $^{29,44}$, their toxicological implications ${ }^{45}$ need to be studied with an ecosystem perspective covering all trophic levels, so that the magnitude of the problem at each level can be ascertained.

Notable quantity of rubber bands was seen in regurgitations of waterbirds from two prominent roosting colonies at Indore and Coimbatore. Many such deceptive artefacts in casually discarded wastes create trouble for birds, at times choking them to death if not for the chronic toxicity of the leachate from such items. Such flaccid artefacts are ingested by birds mistaking them for live organisms. In the present study, almost half of the regurgitated pellets contained rubber bands, balloons and plastic pieces. The instances of these items in regurgitated pellets are indicators of an insidious threat to birds and other wildlife. It poses serious threats to the already threatened migratory species visiting the lakes. Based on the number of pellets that contain these artefacts, Coimbatore, of the two cities studied, seems to be worse in casual treatment of solid wastes.

These artefacts, apart from directly affecting the birds by way of choking their alimentary systems, also cause exposure to toxic chemicals, many of which are known to affect hormonal balance and normal functioning of the biological systems in birds and other animals. The present observations highlight the need for proper management of wastes and further research into the biological and ecological implications of such artefacts being ingested by wild species.

1. Gregory, M. R., Environmental implications of plastic debris in marine settings - entanglement, ingestion, smothering, hangerson, hitchhiking and alien invasions. Philos. Trans. R. Soc. B: Biol. Sci., 2009, 364, 2013-2025.

2. Mrosovsky, N., Plastic jellyfish. Mar. Turtle Newslett., 1981, 17, $5-7$.

3. Pendergrass, R., First a straw, now a fork. Turtles are choking on our plastic trash. Earth Touch News Network, 9 December 2015; http://www.earthtouchnews.com/environmental-crime/pollution/ first-a-straw-now-a-forkturtles-are-choking-on-our-plastic-trash (accessed on 2 February 2016).

4. Grover, A., Gupta, A., Chandra, S., Kumari, A. and Khurana, S. P., Polythene and environment. Int. J. Environ. Sci., 2015, 5(6), 1091-1105.

5. Pruter, A. T., Sources, quantities and distribution of persistent plastics in the marine environment. Mar. Pollut. Bull., 1987, 18, 305-310.

6. Sahu, A. K., Present scenario of municipal solid waste (MSW) dumping grounds in India. In Proceedings of the International Conference on Sustainable Solid Waste Management, September 2007, pp. 5-7.

7. Bennett, G. R., Rubber bands in a Puffin's stomach. Br. Birds, $1960, \mathbf{5 3}, 222$
8. Henry, P. Y., Wey, G. and Balança, G., Rubber band ingestion by a rubbish dump dweller, the White Stork (Ciconia ciconia). Waterbirds, 2011, 34(4), 504-508.

9. BBC, Ducks think rubber bands are food. BBC News, 16 July 2008; http://news.bbc.co.uk/2/hi/uk_news/england/sussex/7508967.stm (accessed on 15 November 2015).

10. Acampora, H., Schuyler, Q. A., Townsend, K. A. and Hardesty, B. D., Comparing plastic ingestion in juvenile and adult stranded short-tailed shearwaters (Puffinus tenuirostris) in eastern Australia. Mar. Pollut. Bull., 2014, 78(1), 63-68.

11. Bassi, N., Kumar, M. D., Sharma, A. and Pardha-Saradhi, P., Status of wetlands in India: a review of extent, ecosystem benefits, threats and management strategies. J. Hydrol. Reg. Studies, 2014, 2, 1-9.

12. Mondhe, B., Khandekar, A. and Rishi, K., Birds of Sirpur, Indore, The Nature Volunteers (TNV), Indore, 2012, p. 176.

13. MoEF, National Wetland Conservation Programme. Guidelines for Conservation and Management of Wetlands in India. Conservation and Survey Division, Ministry of Environment and Forests, Government of India, New Delhi, June 2009, p. 45.

14. Verma, M. A. and Bhonde, B. K., Optimisation of municipal solid waste management of Indore city using GIS. Int. J. Emerging Technol., 2014, 5(1), 194.

15. Pragatheesh, A. and Jain, P., Environmental Degradation of the Coimbatore Wetlands in the Noyyal River Basin, EIA Resource and Response Centre (ERC), Nilgiri, Tamil Nadu, India, 2013, p. 57.

16. Ramakantha, V., Selvan, T. and Ranjit Daniels, R. J., Birds of Coimbatore urban area, India. Tigerpaper, 2005, 32(4), 1-5.

17. Bibby, C. J., Burgess, N. D. and Hill, D. A., Bird Census Techniques, Academic Press Publishers, 1992, p. 257.

18. Ali, S. and Ripley, S. D., Compact Book of the Birds of India, Pakistan Together with those of Bangladesh, Nepal, Bhutan and Sri Lanka, Oxford University Press, Delhi, 1987, 2nd edn.

19. Grimmett, R., Inskipp, C. and Inskipp, T., Birds of the Indian Subcontinent, Christopher Helm, 1998, p. 888.

20. Manakadan, R. and Pittie, A., Standardized common and scientific names of the birds of the Indian subcontinent. Buceros, 2004, 6(1), $1-37$.

21. Fisher, R. J., Fletcher, Q. E., Willis, C. K. R. and Brigham, R. M., Roost selection and roosting behaviour of male common nighthawks. Am. Midl. Nat., 2004, 151(1), 79-87.

22. KoÈrtner, G. and Geiser, F., Roosting behaviour of the tawny frogmouth (Podargus strigoides). J. Zool., 1999, 248(04), 501-507.

23. LaCigüeña, B. C. C., Feeding in urban refuse dumps: ingestion of plastic objects by the White Stork (Ciconia ciconia). Ardeola, 2003, 50(1), 81-84.

24. Moser, M. L. and Lee, D. S., A fourteen-year survey of plastic ingestion by western North Atlantic seabirds. Colon. Waterbird, 1992, 15, 83-94.

25. Derraik, J. G., The pollution of the marine environment by plastic debris: a review. Mar. Pollut. Bull., 2002, 44(9), 842-852.

26. Wu, W.-M., Yang, J. and Criddle, C. S., Microplastics pollution and reduction strategies. Front. Environ. Sci. Eng., 2017, 11(1), 6; doi:10.1007/s11783-017-0897-7.

27. Bourne, W. R. P., Nylon netting as a hazard to birds. Mar. Pollut. Bull., 1977, 8(4), 75-76.

28. Bourne, W. R. P. and Imber, M. J., Plastic pellets collected by a prion on Gough Island, central South Atlantic Ocean. Mar. Pollut. Bull., 1982, 13(1), 20-21.

29. Browne, M. A., Crump, P., Niven, S. J., Teuten, E., Tonkin, A., Galloway, T. and Thompson, R., Accumulation of microplastic on shorelines worldwide: sources and sinks. Environ. Sci. Technol., 2011, 45, 9175-9179.

30. Hays, H. and Cormons, G., Plastic particles found in tern pellets, on coastal beaches and at factory sites. Mar. Pollut. Bull., 1974, 5(3), 44-46. 
31. Teuten, E. L. et al., Transport and release of chemicals from plastics to the environment and to wildlife. Philos. Trans. R. Soc. B: Biol. Sci., 2009, 364(1526), 2027-2045.

32. Colborn, T., vom Saal, F. S. and Soto, A. M., Developmental effects of endocrine-disrupting chemicals in wildlife and humans. Environ. Health Persp., 1993, 101(5), 378-384.

33. Marples, N. M. and Roper, T. J., Effects of novel colour and smell on the response of naïve chicks towards food and water. Anim. Behav., 1996, 51(6), 1417-1424.

34. Guptha, M. B., Vijayan, L., Sandaliyan, S. and Sridharan, N., Status of wetlands and wetland birds in Coimbatore, Trichy, Perambalore and Thiruvarur Districts in Tamil Nadu, India. World J. Zool., 2011, 6(2), 154-158.

35. MUD, Coimbatore Solid Waste Management Project under JnNURM, City Report. Ministry of Urban Development Government of India, July 2013, p. 19.

36. Pettit, T. N., Grant, G. S. and Whittow, G. C., Ingestion of plastics by Laysan albatross. Auk, 1981, 98, 839-841.

37. Fry, D. M., Fefer, S. I. and Sileo, L., Ingestion of plastic debris by Laysan albatrosses and wedge-tailed shearwaters in the Hawaiian Islands. Mar. Pollut. Bull., 1987, 18(6), 339-343.

38. Furness, R. W., Ingestion of plastic particles by seabirds at Gough Island, South Atlantic Ocean. Environ. Pollut. A, Ecol. Biol., 1985, 38(3), 261-272.

39. Ryan, P. G. and Jackson, S., The lifespan of ingested plastic particles in seabirds and their effect on digestive efficiency. Mar. Pollut. Bull., 1987, 18(5), 217-219.

40. Xu, S. Y., Zhang, H., He, P. J. and Shao, L. M., Leaching behaviour of bisphenol: A from municipal solid waste under landfill environment. Environ. Technol., 2011, 32, 1269-1277.

41. Parslow, J. L. F. and Jefferies, D. J., Elastic thread pollution of puffins. Mar. Pollut. Bull., 1972, 3(3), 43-45.

42. Cole, M., Lindeque, P., Halsband, C. and Galloway, T. S., Microplastics as contaminants in the marine environment: a review. Mar. Pollut. Bull., 2011, 62(12), 2588-2597.

43. Martin, W. et al., Microplastics in freshwater ecosystems: what we know and what we need to know. Environ. Sci. Eur., 2014, 26, 12; doi:10.1186/s12302-014-0012-7.

44. Azzarello, M. Y. and Van Vleet, E. S., Marine birds and plastic pollution. Mar. Ecol-Progr. Ser., 1987, 37, 295-303.

45. Ryan, P. G., The effects of ingested plastic on seabirds: correlations between plastic load and body condition. Environ. Pollut., 1987, 46(2), 119-125.

46. Seedikkoya, K., Azeez, P. A. and Shukkur, E. A. A., Cattle Egret Bubulcus ibis habitat use and association with cattle. Forktail, 2005, 21, 174.

47. Santharam, V., Indian pond-herons Ardeola grayii feeding on dragonflies. J. Bombay Nat. Hist. Soc., 2003, 100(1), 108.

ACKNOWLEDGEMENTS. We are grateful to Dr K. Ramasamy (then Vice Chancellor, TNAU) for permitting this study in TNAU Campus. We thank Dr P. Balasubramanium (Department of Biochemistry, TNAU), Dr Shirish S. Manchi and Dr M. Mahendiran (SACON) for their support. We also thank Mr Avadhoot Dilip Velankar, Mr M. J. Riyas and Ms Anju R. Panickar for assistance with QGIS software. Our special thanks to M/s Mukesh Lal Das, Gopesh Sharma, and Manish Kumar for their assistance during the study.

Received 16 July 2019; revised accepted 8 November 2019

doi: $10.18520 / \mathrm{cs} / \mathrm{v} 118 / \mathrm{i} 6 / 977-983$

\section{Tunnel wells, the traditional water harvesting structures of Kasaragod, Kerala: re-visited}

\author{
E. Shaji ${ }^{1, *}$, K. V. Sarath ${ }^{1}$, Pranav Prakash ${ }^{1}$, \\ Adithya Pazhoor Abraham ${ }^{2}$, V. Deepchand, \\ V. Kunhambu ${ }^{3}$ and A. P. Pradeepkumar ${ }^{1}$ \\ ${ }^{1}$ Department of Geology, University of Kerala, \\ Thiruvanathapuram 695 581, India \\ ${ }^{2}$ Department of Civil Engineering, National Institute of Technology, \\ Calicut 673 601, India \\ ${ }^{3}$ Central Ground Water Board, Kerala Region, \\ Thiruvanathapuram 695 004, India
}

Tunnel wells or surangams are less common traditional groundwater harvesting structures of Kasaragod district in Kerala, southern India. These horizontal wells, structurally resembling Qanats, are driven into the laterite plateaus and hills for tens of metres. The status of tunnel wells of Kasaragod is synthesized, the problems and prospects examined to evolve a common strategy for sustainability. Functionally four different types of tunnel wells exist: (1) single tunnel, (2) single tunnel with branches, (3) tunnel system ending in a vertical well, and (4) tunnel system ending in a well with a horizontal outlet. The yield of tunnel wells has reduced over the years and $50 \%$ of them are now dry. Single tunnels (types 1 and 2) act as conduits for excessive draining of groundwater from the aquifer system during the rainy season, leading to wastage of groundwater and lowering the water table. The discharge estimates from the 24 tunnel wells indicate that $6653 \mathrm{~m}^{3}$ of groundwater gets discharged from the aquifer per day. To prevent wastage, the mouth of the tunnel wells should be fitted with half shutter gate with a control valve at the bottom. There is an urgent need to create awareness to protect and modify these traditional water harvesting structures for sustainability of water resources.

Keywords: Discharge, groundwater, Kasaragod, traditional water harvesting, tunnel wells, surangam.

TRADITIONAL water harvesting structures generally provide time-tested solutions to water scarcity problems in many parts of India $^{1-6}$. Tunnel wells or surangams are less well known and are gradually disappearing traditional groundwater harvesting structures of Kasaragod district, Kerala, southern India ${ }^{6-11}$. The word surangam is derived from a Kannada word for tunnel. It is also known as thurangam, thorapu, malayoottu, etc. These horizontal wells driven into the laterite plateaus and hills, structurally resemble Qanats ${ }^{1}$ found in the arid regions of south-western Asia and North Africa, running several kilometres underground and are in use since generations. Probably the

*For correspondence. (e-mail: shajigeology@gmail.com) 